\title{
DISTRIBUTED TRAINING, CAX AND EXPERIMENTATION IN SUPPORT OF CRISIS MANAGEMENT
}

\author{
Orlin NIKOLOV
}

\begin{abstract}
This paper addresses multinational and interagency cooperation in efforts to create expertise in the crisis management area. The focus is on using a simulation environment and conducting Computer Assisted eXercises (CAX) in order to enhance NATO-EU relations through development of military capabilities. More specifically, it is about how the EU and NATO and their Member States should pursue multinational projects and deliver the military capabilities they need and can use not only for military purposes but for crisis management in support of civilian authorities as well. Finally, it presents ongoing Bulgarian activities towards the creation of a Centre of Excellence in Crisis Management and Disaster Relief in support of the efforts of the EU and NATO to develop capabilities in areas where both organizations have the same requirements and similar shortfalls.
\end{abstract}

Keywords: CAX, multinational exercise, disaster relief, comprehensive approach, NATO-EU cooperation, civil-military interoperability, interagency cooperation, defence support to civilian authorities.

\section{Introduction}

The nature of the conflict and of the operations conducted by NATO has a profound impact on the requirements towards the armed forces. Rather different types of units have to be prepared, and the way they are structured and their worth evaluated has also changed significantly. Cooperation and interoperability between civilian and military units, especially in crisis management, countering terrorist threats, protecting strategic infrastructure, etc. is among the top priorities in EU Security and Defence Policy, NATO and Nations.

In addition, allies face a severe financial crisis. Hence, if one would like to enhance the Alliance ability to anticipate the emerging security challenges, and to adapt its capabilities accordingly, it is necessary to make more effective and efficient use of the resources currently available. 
What we need to do is to make sure that the resources we devote to defence are used in the best possible way. NATO Secretary General Anders Fogh Rasmussen underlined six ways in which we can do that: ${ }^{1}$

1. Prioritization;

2. Collective solutions;

3. Common funding;

4. Specialization;

5. Avoiding duplication;

6. Reform.

In short, NATO must be a faster, more efficient service provider for its member nations. One priority is to reform NATO's own command structure by making the structure leaner, more effective and less costly.

In all these areas, the biggest reform challenge is to change our mindset. Twenty years after the end of the Cold War, we still have not fully shifted our focus from planning to action and implementation. NATO should complete that shift in the next decade.

Current and emerging operational requirements demand broader and deeper levels of interoperability and integration between NATO and Nations' headquarters and forces. Enhanced capabilities such as unmanned aerial vehicles, joint intelligence, surveillance and reconnaissance capabilities, friendly force trackers, C-IED, and cyber defence are being integrated into ISAF and the preparation for NATO Response Force (NRF) operations. New capabilities such as the Air Command and Control Systems (ACCS), Airborne Ground Surveillance (AGS) and Active Layer Theatre Ballistic Missile Defence (ALTBMD) are also maturing. Additionally, NATO is increasingly operating alongside non-NATO military and non-military players, which is placing new demands on current NATO tactics, techniques, and procedures. This combination of enhanced capabilities and evolving operational requirements are putting news demands on how we train our headquarters and forces to ensure NATO and national command and control systems, weapon systems and tactics, techniques and procedures are all interoperable with each other and - where appropriate- - with other coalitions partners. This is true from the highest levels of the NATO Command Structure (NCS) down to the lowest levels of the NATO Force Structure (NFS). For all these reasons there is a urgent need for a common NATO training and education distributed environment where the NCS and NFS, and also NATO nations and partners can routinely train "as they fight" to boost standardization and interoperability, and at the same time reduce duplication of effort and enhance the efficiency in using limited resources. ${ }^{2}$ 


\section{Bulgarian Experience and Multinational Cooperation}

The Bulgarian Armed Forces have already gained experience in conducting different types of exercises, simulation of crises and operations other than war with different structures. At this stage, one of our major tasks is to develop specialized centres with a broad spectrum of capabilities for interaction of the Ministry of defence (MoD) with other ministries, civil agencies and organizations within the framework of the civil-military cooperation. The efforts of the majority of Balkan nations are focused on that perspective, too.

In response to ACT's call for national experiment proposals, Bulgaria submitted a proposal for a complementary set of experiments to be conducted in conjunction with Exercise Phoenix 2010, a Bulgarian national Command Post Exercise. This proposal was reviewed at the CD\&E Working Group and included in ACT's integrated programme of experiments. Planning continued throughout 2009 and 2010 and culminated in an exercise in Bulgaria at the end of 2010.

From a NATO point of view, Phoenix 2010 was an extremely valuable exercise. As regard to preparations for NATO Stabilization and Reconstruction operations, Bulgaria demonstrated a serious Crisis Management programme in place and an ambition to further improve it. Phoenix 2010 provided an opportunity for NATO to observe first-hand how a Nation's ministries would deal with a crisis providing multiple ministry support and creating ad-hoc solutions when current Standard Operating Procedures (SOP) failed to address all related issues. Bulgaria demonstrated that within the Nation, functional crisis response capabilities fall under various ministries and the organizational alignment and execution capabilities are the responsibility of the respective ministries. This is similar to most (if not all) NATO nations and indicates that future developments in NATO Crisis Management should focus on provision of common capabilities that are designed to be shared between independent organizations (ministries or government agencies) rather than providing a functional enhancement that might overlap with existing Government organizations and therefore be more difficult to implement. ${ }^{3}$

As the planning evolved it became apparent to ACT that they could execute more of their planned experiments in conjunction with Bulgarians and this created a situation where ACT and Bulgaria contributing as partners in experimentation, achieved more together than when conducting experiments as separate events.

That partnership continues and will grow through the years. This year a multinational Computer Assisted Exercise (CAX) "Energy Flame 2011" will be conducted. Utilising modelling and simulation environment, the concept of the exercise will address energy security aspects and stabilization and reconstruction in the Balkans after energy crises. 
The exercise involves nine countries from the Balkan region - Albania, Bosnia and Herzegovina, Bulgaria, Greece, Montenegro, Romania, the Former Yugoslav Republic of Macedonia, Turkey, and Serbia. ACT participates in the experimental part with conducting two experiments - Strategic Communication and CLOVIS (Civil Military Legal Overview Virtual Information System).

This activity builds on earlier regional cooperation efforts. ${ }^{4}$ On 9 October 2000, the ministers of defence from the region agreed to move forward with the Southeast Europe Defence Ministerial (SEDM) initiative through a series of simulation-based exercises called the South Eastern Europe Simulation Network (SEESIM) as a tool for integration, cooperation and coordination among the SEDM nations.

The purpose of the exercise is to promote cooperation, coordination and interoperability of civil-military operations and reinforce real world crisis response within and among the SEDM nations and the SEDM initiatives through effective use of computer modelling and simulation (M\&S). The specific aim is to develop the capabilities and procedures of national and regional coordination, cooperation, and mutual assistance among the SEDM nations in the face of devastating emergencies, such as natural disasters or terrorist attacks.

As a real example of multinational cooperation, is a process of obtaining fragments of ICC (Integrated C2) that will allow to become part of NATO's common ACCS (Air C2 System). Additionally, Bulgaria is interested in having access to the CFBLNET (Combined Federated Battle Laboratories Network).

Next, Bulgaria is in a process of considering the potential participation in the project for "Multinational procurement of NATO Air Surveillance Sensors (RADAR)." This is a Balkan Regional Approach to build and maintain air defence capabilities and enhance the operability and sustainability.

\section{Persistent Training and Simulation Capabilities}

In 2008 Bulgaria hosted the SEESIM exercise. Next year it will host again SEESIM 2012. Together with the US Joint Coalition and Warfighting Center (JCWC), we will change the format of conducting the exercise and will involve more NATO organizations to discuss possible roles and take advantage of potential cost-saving synergies while anchoring at the same time SEESIM more firmly in the NATO political, operational and technical orbit.

HQ Allied Command of Transformation (ACT), Joint Warfare Center (JWC), Joint Force Training Center (JFTC), NATO Consultation, Command and Control Agency (NC3A) and CoE for Modelling and Simulation (CoE M\&S) would support and participate in SEESIM 2012 pertaining to the conduct of the ACT Distributed Training 
and Exercise experiment; support to the Bulgarian national experiment; training and expertise in SEESIM 12 planning and execution; attendance in SEESIM 12 planning conferences, preparation and exercise execution; and the establishment of a network to enable the achievement of experimentation objectives.

The established M\&S environment should encompass the tools, procedures, interoperability standards and means in order to facilitate reach back to capabilities within relevant NATO centres, agencies or centres of excellence, as well as to provide simulation environment required to train and assess expeditionary forces, gain situational awareness for crisis response operation, and enhance the interoperability with civil authorities and NATO organizations.

The exercise will allow thus to test the federation of the regional simulation centres in a common network for exercises and training (South Eastern Europe Exercising and Training Network - SEEETN) and its connection to the NATO Distributed Training and Exercises Network (DTE). In addition, NATO organizations will experiment and test the NATO Training Federation between the simulation systems JTLS, JCATS and VBS2 in addition with other tools used in NATO and members states.

The experimental aim of SEEETN is to establish the M\&S environment required for planning, training, concept development and experimentation for the purpose of Education and Training (E\&T) at national and, subsequently, at regional level.

This environment should encompass the tools, procedures, interoperability standards and means in order to facilitate reach back to capabilities within relevant NATO centres, agencies or centres of excellence, as well as to provide simulation environment required to train and assess expeditionary forces, situational awareness for crisis response operation, interoperability with civil authorities and NATO organizations.

The experiment pursues the following objectives:

- To develop simulation capabilities, e.g. planning tools and models, tools for situation awareness and analysis;

- To create multi resolution federation for disaster management and emergency response;

- To enhance the capabilities of the National Military Training Complex;

- To create persistent distributed National Training and Simulation Capabilities.

\section{CoE in Crisis Management and Disaster Relief}

Crisis management and disaster relief are core NATO tasks. Today the Alliance is able to take decisions in a crisis, and to act under significant threat and time pressure. 
NATO develops capabilities to be ready, on a case-by-case basis and by consensus, to contribute to effective conflict prevention and to engage actively in crisis management, including through non-Article 5 crisis response operations.

NATO Summits' Declarations and the Strategic Concept emphasize the need for NATO to enhance its contribution to a Comprehensive Approach to crisis management, based on the recognition that military intervention alone cannot resolve a crisis. As a result, a number of ongoing activities in NATO on the comprehensive approach respond to the need to enhance Nations' capabilities for better civil-military interaction and crises and disasters response.

Ensuring greater security requires that NATO sets the right priorities and strategic direction, to identify possible areas of cooperation, and to share best practices, lessons learned and capabilities. Close cooperation in the crisis management domain requires forming appropriate capabilities for intelligence and information sharing, for early warning and situational awareness as well for conducting crisis management planning. The Alliance is therefore emphasizing joint training of civilian and military personnel that helps to build trust and confidence. In congruence with the comprehensive approach to respond to these needs, Bulgaria proposed acting as a Framework Nation for the establishment of a NATO Crisis Management \& Disaster Relief Centre of Excellence.

In support of NATO transformation, nations create a wide network of Centres of Excellence (CoEs). They are nationally and multinationally managed and funded entities that provide a wide range of opportunities for capabilities building: improving interoperability and capabilities with education and training of leaders and units from NATO, PfP Partners, Mediterranean Dialogue Partners, Istanbul Cooperation Initiative, Partners across the globe; testing doctrines; developing and validating concepts through experimentations, providing Lessons Learned evaluations and assessments.

The concept for the CoE in Crisis Management and Disaster Relief promotes the fundamental aspects of its establishment and functioning, and covers the following areas:
a. Guiding Principles and Core Values;
b. Operational Requirements;
c. Vision;
d. Mission;
e. Functions, Activities, and Deliverables;
f. Location;
g. Organization;
h. Command Relationships; 
i. Functional Relationships;

j. Responsibilities and support functions;

k. Annexes:

- Annex A: Definitions;

- Annex B: CM\&DR COE Organizational chart.

\section{Vision}

The vision for the Centre comprises the following ends, ways, and means:

- With the effort of the Nations with common goals, to establish and maintain an internationally recognized and respected centre for contributing with its activities for research, building and development of NATO and Nations Crisis Management \& Disaster Relief capabilities;

- To become NATO transformation expert and adviser in the area of Crisis Management \& Disaster Relief;

- To be a part of a bridge for close cooperation between NATO and the European Union within an agreed framework in the development of an international comprehensive approach to crisis management and disaster relief capabilities that requires effective application of both military and civilian means;

- To apply a comprehensive approach in education and training that supports NATO, Nations and partners in building the appropriate military and civil capabilities for:

o Improving knowledge development and sharing in the domain of crisis management and disaster relief;

o Training nations' and partners' personnel in NATO crisis management and disaster relief policy and standards, as well tactics, techniques and procedures for application crisis/disaster preventive and response measures;

o Helping to develop and apply appropriate Crisis Response Measures that prevent crises from arising and their evolution into conflicts;

o Training to effectively employ civil and military capabilities in Crisis Response Operations and Disaster Relief Operations;

o Training to carry out planned activities that prevent population and critical infrastructures from disasters, as well to conduct disaster relief operations. 
- In coordination with related allied and international institutions and agencies, to develop and maintain an internationally recognized education and training institution that will be a focal point for the Community of Interests in the area of CM\&DR.

- To foster a continuous self-development of the CM\&DR COE by conducting result-oriented research, studies, experiments, giving direction and providing education and training as a complete concrete contribution to crisis management and disaster relief.

- To define, and develop programmes and tools in support of a common network for exercising and training between NATO and partners in order to harmonize civil and military capabilities for conducting Exercises and Experiments in CM\&DR.

\section{Mission}

The mission of the NATO CM\&DR COE is to enhance NATO and NATO nation's crisis management and disaster relief capability development in support of NATO transformation.

The NATO CM\&DR COE will be located in Sofia, Bulgaria, making the best usage of the existing national military education and training facilities, the National Training Centre Charalitza, Training centre for Disaster Relief of the Ministry of the Inerior, and national training centres of other institutions. That $\mathrm{CoE}$ will be the first one

\section{CM\&DR COE ORGANIZATIONAL CHART}

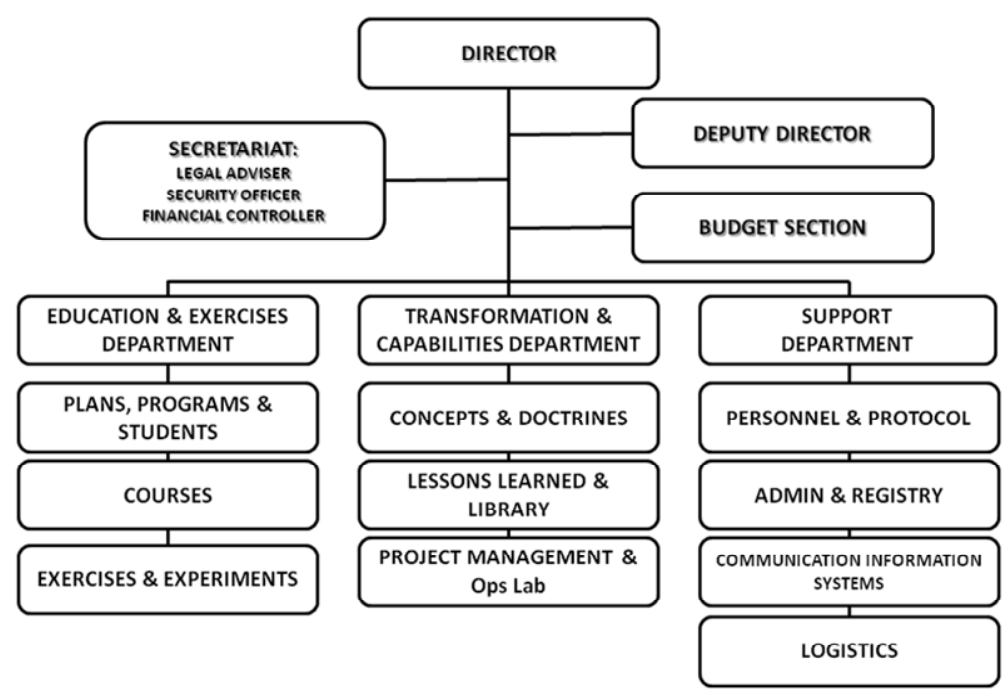


where the personnel will work together for unification of the expertise in interagency multinational environment. That could be the next step of Comprehensive approach.

\section{Conclusion}

NATO and the European Union (EU) share common values and strategic interests, and are working side by side in crisis management operations. At the Lisbon Summit in November 2010, the Allies underlined their determination to improve the NATOEU strategic partnership, as agreed by the two organizations.

The financial crisis will further facilitate the cooperation between NATO and the European Union as an important element in the development of an international comprehensive approach to crisis management and operations, which requires the effective application of both military and civilian means. Creating common multinational permanent environment and expertise for preparation of our troops and forces will increase our abilities for training and education and will erase the boundaries between nations. Furthermore, creating new capabilities will give us new opportunities to participate more effectively in the crisis management process, what is the future of using armed forces.

The COE will involve a lot of civilian potential for experimentations of different types of operations in all kinds of crises. That will help to achieve commonality of Standard Operational Procedures, doctrines and concepts, will decrease the boundaries and accelerate the transformation and close cooperation between NATO and the EU.

\section{References:}

1 Address by NATO Secretary General Anders Fogh Rasmussen at the Belgian Royal High Institute for Defence.

2 NATO's new Strategic Concept: Report of the Group of Experts, 14 May 2010.

3 ACT Stabilization and Reconstruction report after Phoenix 2010 exercise, February 2010.

4 See for example Petya Dimitrova, "Networking South East Europe in Managing Nontraditional Challenges," Information \& Security: An International Journal 10 (2003): 59-72; and Todor Tagarev, "Developing South East European Cooperative Crisis Management Capacity,” Information \& Security: An International Journal 10 (2003): 73-83.

ORLIN NIKOLOV is a Lieutenant Colonel, currently serving in the Operation and Training Directorate of the Defence Staff in the Ministry of Defence of the Republic of Bulgaria.

E-mail: o.nikolov@mod.bg. 